\title{
Basilar Artery Blood Flow in Subclavian Steal
}

\author{
Natan M. Bornstein, Adam Krajewski and John W. Norris
}

\begin{abstract}
Subclavian "steal", when blood siphons from one vertebral artery to the other, has been suggested as a cause of brain stem ischaemia and stroke. We investigated 33 patients using transcranial Doppler to determine the direction and velocity of basilar blood flow. All patients had severe subclavian stenosis with reversed vertebral blood flow in the ipsilateral artery previously demonstrated by extracranial Doppler. Basilar flow was normal in direction in all cases, but its velocity was significantly increased $(\mathrm{p}<0.0008)$ compared to age- and sex-matched controls. These findings, in conjunction with previous observations using extracranial Doppler techniques, suggest that subclavian steal is little more than a harmless haemodynamic phenomenon.
\end{abstract}

RÉSUMÉ: Le flot artériel basilaire dans le syndrome de détournement sous-clavier Il a été suggéré que le syndrome de détournement sous-clavier, syndrome dans lequel le sang siphonne d'une artère vertébrale à l'autre, peut être une cause d'ischémie et d'infarctus du tronc cérébral. Nous avons investigué 33 patients par ultrasonographie par effet Doppler transcrânienne afin de déterminer la direction et la vélocité du flot sanguin basilaire. Tous ces patients avaient une sténose sous-clavière sévère avec renversement flot sanguin vertébral dans l'artère ipsilatérale au Doppler extracrânien. La direction du flot basilaire était normale dans tous les cas, mais sa vélocité était significativement augmentée $(p<0.0008)$ par rapport à celle de contrôles appariés pour l’âge et le sexe. Ces données, de même que les observations antérieures obtenues par techniques Doppler extracrâniennes, suggèrent que le syndrome de détournement sous-clavier est un prénomène hémodynamique anodin.

Can. I. Neurol. Sci. 1988; 15:417-419

It was first suggested in 1837 that retrograde flow could occur through collateral channels into the distal portion of the subclavian artery beyond a proximal occlusion. ${ }^{1}$ Reivich and colleagues $^{2}$ suggested that this phenomenon, named "subclavian steal" by Fisher, ${ }^{3}$ might cause transient brain stem ischaemia or stroke, either spontaneously or secondary to arm exercise. They hypothesised that blood siphons from one vertebral artery into the other, stealing blood from the basilar artery.

Our previous observations of patients with subclavian steal suggest it is a relatively benign haemodynamic phenomenon which rarely produces cerebral sequelae. ${ }^{4}$ The recent introduction of transcranial Doppler permits noninvasive examination of blood flow through the circle of Willis, including the basilar artery, ${ }^{5-8}$ facilitating more direct observation of the haemodynamics of subclavian and vertebrobasilar blood flow. We examined clinically, and with transcranial Doppler, at rest and during arm exercise, 41 patients with severe subclavian stenosis, of whom 33 had reversed vertebral blood flow. The resulting data confirm our previous observations using extracranial Doppler ${ }^{4}$ and challenge the hypothesis that subclavian stenosis can cause brain stem symptoms by stealing blood from the basilar artery.

\section{Patients and Methods}

Thirty-three patients (14 men, 19 women, mean age 65 years) with a positive subclavian-steal test previously demonstrated with continuous-wave Doppler (Carolina Medical Electronics Dopscan 1050$)^{4}$ were re-assessed. The indications for doing the subclavian steal test were: 1) $20 \mathrm{~mm} \mathrm{Hg}$ bloodpressure difference between the arms; 2) A monophasic waveform from the subclavian artery, indicating severe subclavianartery stenosis (the normal wave form being triphasic).

The subclavian steal test consists of Doppler ultrasonography of the vertebral artery with the patient at rest and with a blood pressure cuff applied to the arm ipsilateral to the arterial stenosis. The cuff is inflated above systolic pressure for three minutes.

The patient exercises the arm vigorously during the last two minutes of occlusion and the cuff is quickly deflated. The test is positive if complete reversal of vertebral flow occurs. This time they underwent continuous-wave Doppler of the carotid, subclavian and vertebral arteries, with transcranial Doppler evaluation of the direction and velocity of vertebrobasilar blood flow

From the Stroke Research Unit, Sunnybrook Medical Centre, University of Toronto, Toronto

Received December 1, 1987. Accepted in final form May 24, 1988

Correspondence to: J.W. Norris, MD, Sunnybrook Medical Centre, 2075 Bayview Avenue, Toronto, Ontario, Canada M4N 3M5 
before, during and after the subclavian-steal test. The transcranial Doppler system (EME TC2-64, Carolina Medical Electronics) consists of a range-gated pulsed Doppler ultrasound system with frequency analysis, and continuously computed blood flow velocities, using a 2 megaHertz probe. To evaluate the basilar artery the probe is pressed against the midline of the nape of the neck, aiming the ultrasound beam upwards through the foramen magnum (Figure 1). The basilar artery usually lies at a distance of at least $75 \mathrm{~mm}$ along an oblique axis. ${ }^{8}$ To identify the proximal basilar artery we assessed its flow at $90-100 \mathrm{~mm}$ depth, and then traced its flow caudally to the confluence of the distal vertebral arteries. An abrupt change of frequency usually identifies the confluence of the basilar and vertebral arteries. The vertebral and the basilar arteries are the most consistently recorded with the transcranial Doppler.

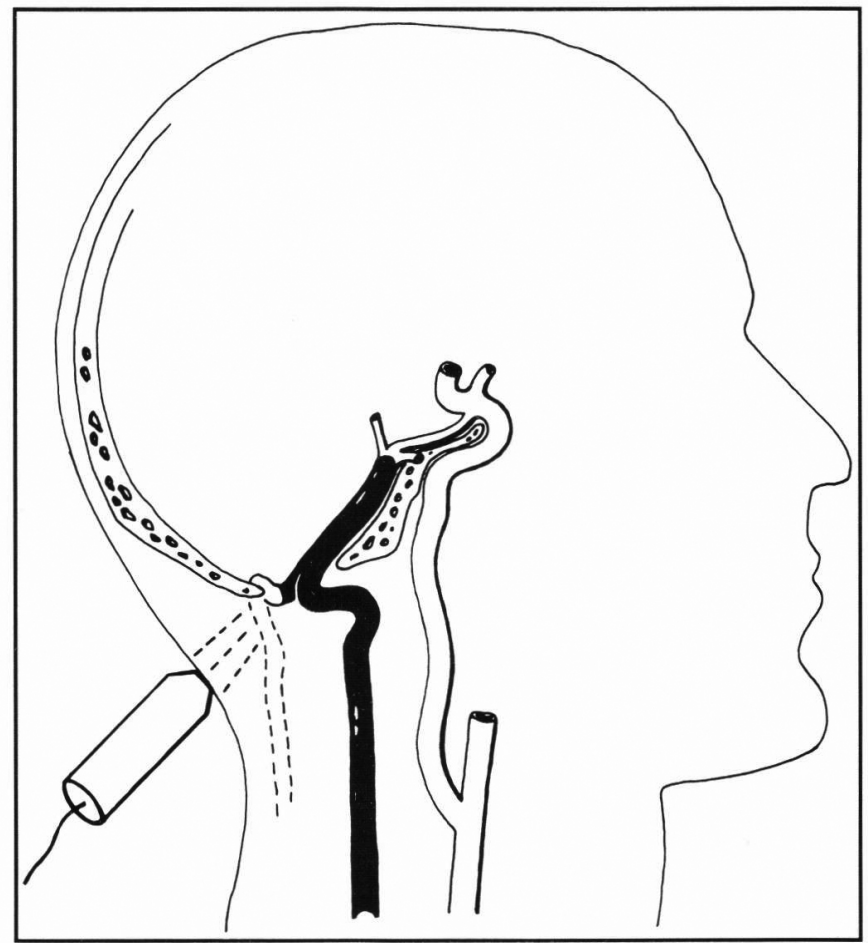

Figure I - Schema of vertebrobasilar blood flow assessment transcranially through the foramen magnum.

The accuracy of the transcranial Doppler in detecting the basilar artery flow direction is $100 \%$.

Eight patients with severe subclavian stenosis but without vertebral flow reversal, and 18 age- and sex-matched healthy volunteers with normal carotid Doppler examinations were also examined.

Student's t-test was used to test the comparability of the blood velocity in the basilar artery in the patients and the controls and a non-parametric Wilcoxon 2-sample test was used to corroborate the t-test. A paired t-test was used to test for any significant change in blood velocity in the basilar artery before and after the subclavian-steal test. A one-way analysis of variance (ANOVA) was performed comparing basilar artery velocity in patients with (a) subclavian steal, (b) subclavian stenosis without "steal", and (c) controls without arterial disease.
Tukey's pair-wise comparison was used to test for significant differences between groups after a significant main effect for group for the ANOVA was found.

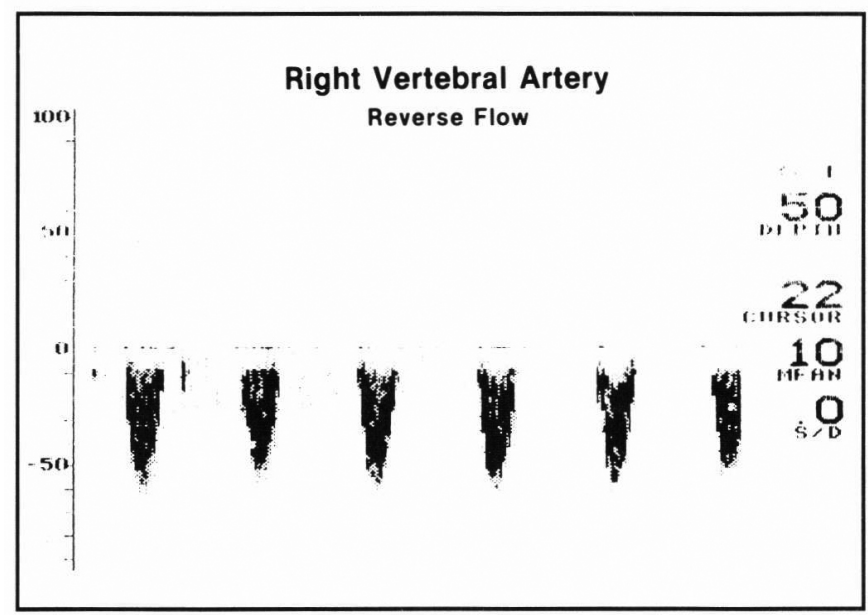

Figure $2-a)$ Reversed flow in the right vertebral artery during the steal test, depth $50 \mathrm{~mm}$ peak velocity $92 \mathrm{~cm} / \mathrm{sec}$.

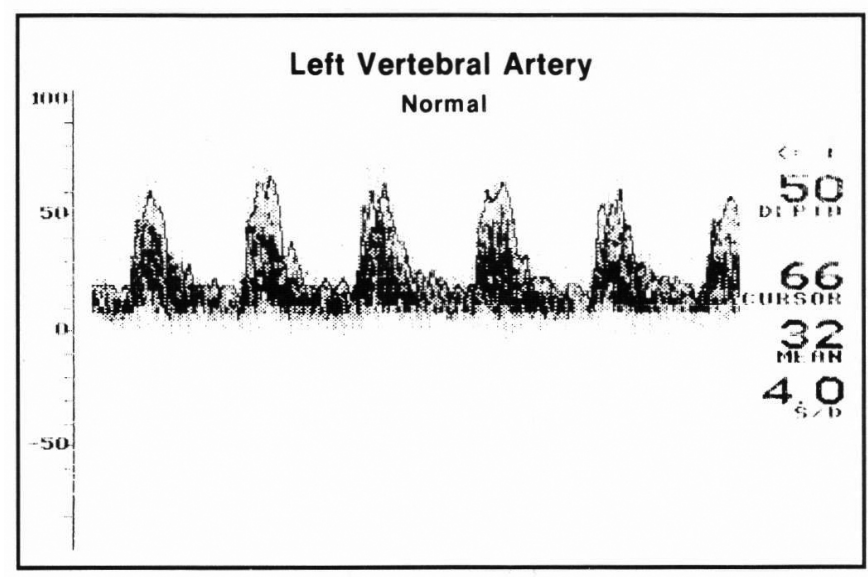

Figure $2-\boldsymbol{b})$ Normal direction of flow in the left vertebral artery, depth $50 \mathrm{~mm}$, peak velocity $86 \mathrm{~cm} / \mathrm{sec}$.

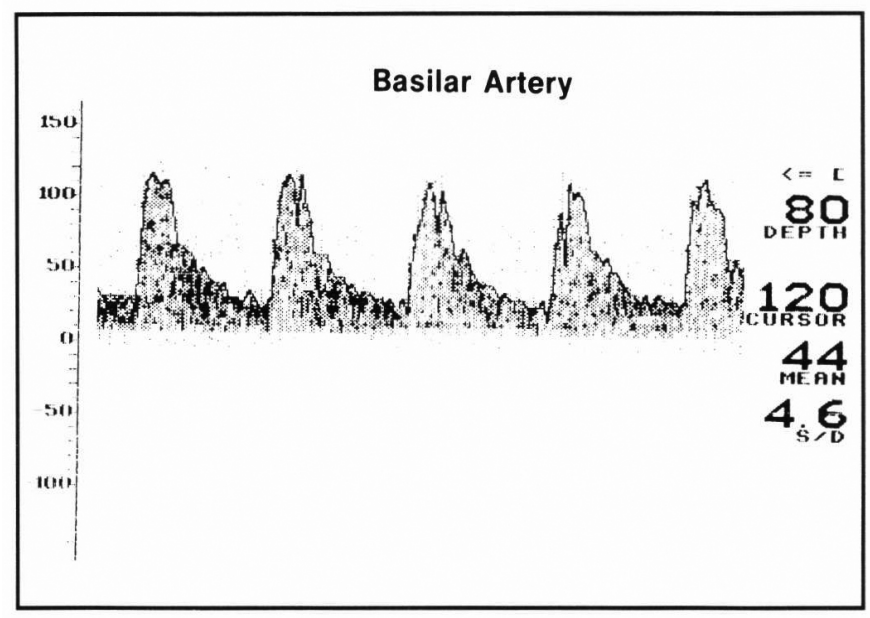

Figure 2 - c) Normal direction of flow in the basilar artery, depth $80 \mathrm{~mm}$, peak velocity $110 \mathrm{~cm} / \mathrm{sec}$ (normal range $55-70 \mathrm{~cm} / \mathrm{sec}$ ). 
Table 1: Peak Velocities of Blood Flow in the Basilar Artery.

\begin{tabular}{lccc}
\hline \hline & $\begin{array}{c}\text { Number of } \\
\text { Patients }\end{array}$ & $\begin{array}{c}\text { Mean Peak } \\
\text { Velocity }\end{array}$ \\
\hline Subclavian steal & resting & 33 & $83^{*}$ \\
& after cuff test & 33 & 83 \\
Severe subclavian stenosis without steal & 8 & 71 \\
Controls & 18 & 58 \\
\hline
\end{tabular}

${ }^{*} p<0.0008$ compared to controls (with Bonferroni correction, significant $p$ was accepted at 0.01 ).

\section{Results}

None of the patients had reversed or bidirectional flow in the basilar artery before, during, or after the steal test (Figure 2). No patients developed symptoms during the steal test despite reversed vertebral flow. None developed ischaemic cerebral symptoms during 36 months' follow-up.

The mean peak velocity in the basilar artery was significantly higher in patients with subclavian steal than in controls $(p<0.0008)$, but there was no difference between velocities at rest compared to velocities after the arm cuff was deflated (Table 1). Although peak velocities in the basilar artery were higher in patients with severe subclavian stenosis without steal, this difference was not significant.

When mean peak basilar blood flow was compared in 11 patients with bidirectional vertebral flow at rest and 22 patients with reversed vertebral flow at rest, the results were identical $(83 \mathrm{~cm} / \mathrm{sec}$ in both groups).

Duplex scanning of the extracranial carotid circulation indicated that half of the patients had carotid stenoses of less than 50 percent ( 16 patients), while nine patients had 50 to 75 percent stenosis of at least one artery. Of the remaining eight patients, five had bilaterally severe (greater than 75 percent) stenosis and three had unilateral severe stenosis.

\section{DISCUSSION}

These data support our previous observation that reversed blood flow in the vertebral artery is a benign haemodynamic phenomenon which rarely produces symptomatic brain stem ischaemia. Since none of our patients with subclavian steal had reversed flow in the basilar artery at rest or during the subclavian-steal test, brain stem ischaemia, if it occurred, could not result from blood siphoning across the basilar artery from the opposite vertebral artery. 2,3

Hennerici and colleagues found reversed flow in the basilar artery on transcranial Doppler evaluation of two of 55 patients. Both presented with vertebrobasilar TIAs but neither had stroke and their symptoms were not related to arm exercise. ${ }^{9}$

Our data do not support the suggestion that neurological symptoms occur only when subclavian steal is concurrent with haemodynamic incompetence elsewhere in the cerebral circulation, ${ }^{10,11}$ since as many patients had trivial as had severe carotid disease.

The high blood velocity detected in the basilar artery of patients with subclavian steal might result from reduced blood flow to the basilar artery producing reduced capacitance and increased velocity through a smaller calibre vessel, or from compensatory increased flow in the normal vertebral artery or collaterals.

Although we do not dispute the demonstration by angiography and ultrasonography of reversed blood flow in a vertebral artery ipsilateral to severe subclavian stenosis, there appears to be no evidence for the postulated reversal of blood flow in the basilar artery or for clinical ischaemic sequelae.

\section{ACKNOWLEDGEMENTS}

Dr. Bornstein is a Research Fellow of the Medical Research Council of Canada, and this project was partly funded by grant MA-8924 from the Medical Research Council of Canada. Dr. Krajewski is a Research Fellow of the Canadian Heart Foundation. We thank Lorraine Chadwick and Susan Corrigan for performing the Doppler examinations, Cecily Ziliotto for managing the data and Barbara Huth for editing the manuscript.

\section{REFERENCES}

1. Fields WS. Reflections on "the subclavian steal". Stroke 1970; 1: 320-324.

2. Reivich M, Holling HE, Roberts B, et al. Reversal of blood flow through the vertebral artery and its effect on cerebral circulation. N Engl J Med 1961; 265: 878-885.

3. Editorial: A new vascular syndrome - "the subclavian steal". N Engl J Med 1961; 265: 912-913.

4. Bornstein NM, Norris JW. Subclavian steal: a harmless haemodynamic phenomenon? Lancet 1986; ii: 303-305.

5. Aaslid R, Markwalder TM, Nornes H. Non-invasive transcranial Doppler ultrasound recording of flow velocity in basal cerebral arteries. J Neurosurg 1982; 57: 769-774.

6. Halsey JH, McDowell HA, Gelman S. Transcranial Doppler and rCBF compared in carotid endarterectomy. Stroke 1986; 17: 1206-1208.

7. von Reutern GM. Functional and morphological evaluation of the cerebral circulation by ultrasound. In: Poch K, Freund HJ, Ganshirt H, eds. Neurology. Berlin, Springer 1986: 441-452.

8. Arnolds BJ, von Reutern G-M. Transcranial Doppler sonography. Examination technique and normal reference values. Ultrasound Med Biol 1986; 12: 115-123.

9. Hennerici M, Klemm C, Rautenberg W. The subclavian steal syndrome: a common vascular disorder with rare neurologic deficits. Neurology 1987; 37(suppl 1): 316.

10. Heyman A, Young WG, Dillon M, et al. Cerebral ischemia caused by occlusive lesions of the subclavian or innominate arteries. Arch Neurol 1964; 10: 581-589.

11. Lord RSA, Adar R, Stein RL. Contribution of the circle of Willis to the subclavian steal syndrome. Circulation 1969; 40: 871-878. 